\title{
The Effects of Cognitive Behavior Therapy and Social Skill Training among Schizophrenia with Risk of Violent Behavior
}

\author{
Nurlaila Fitriani $^{1,2 *} \mathbb{D}$, Budi Keliat ${ }^{1 *} \mathbb{D}$, Ice Yulia Wardani $i^{1} \mathbb{D}$ \\ ${ }^{1}$ Department of Mental Health Nursing, Faculty of Nursing, Universitas Indonesia, Jakarta, Indonesia; ${ }^{2}$ School of Nursing, \\ Faculty of Health Sciences, Universitas Muhammadiyah Surakarta, Jawa Tengah, Indonesia
}

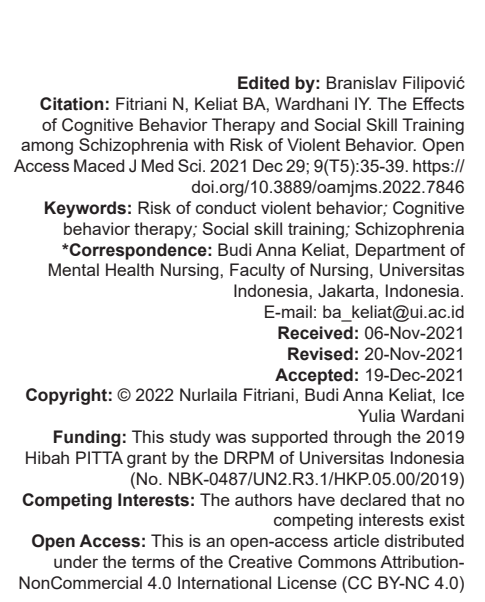

\section{Abstract}

BACKGROUND: Schizophrenia is a condition in which people suffer from impaired ability to think, perceive, and show emotional responses and interact socially. Patients with schizophrenia can experience the risk of violent behavior (RVB). Psychotherapy is needed to deal with the problem.

AIM: This study aimed to investigate the effects of cognitive behavior therapy (CBT) and social skill training (SST) on signs and symptoms of risks of violent behavior (RVB).

METHODOLOGY: This study employed a quasi-experimental without a control group. The research samples used purposive sampling were 30 patients with symptoms of risks of violent behavior. Meanwhile, the measurement used the sign and symptom questioners of risks of violent behavior $(Z=0.791)$.

RESULT: This study revealed that signs and symptoms decreased significantly $(p<0.05)$ from 10.45 to 5.41 after the respondents had obtained the CBT. Moreover, after the respondents had received CBT and SST, the sign and symptoms decreased significantly $(\mathrm{p}<0.05)$ from 5.41 to 0.52 .

CONCLUSION: This study recommends that the combination of CBT and SST be administered to patients with schizophrenia with risks of violent behavior.

\section{Introduction}

Schizophrenia is a severe and chronic mental illness that affects about 20 million people with an average of $1.5 / 10.000$ people worldwide [1]. Therefore, schizophrenia is included in the top three of the mental illness that causes disability and contributes $12.2 \%$ (9.6-15.2) of the total DALYs of mental disorders [2]. Schizophrenia cases in Indonesia have increased from $1.7 \%$ to $1.8 \%$ from 2013 to 2018 [3].

Schizophrenia is a condition in which people suffer from impaired thinking, perception, emotional responses, and social interaction [1]. These symptoms lead to a condition in which people have severe mental disabilities [4]. As a result, they experience decreasing education, work, coping mechanisms, and social relationships [5]. Schizophrenia is a chronic and persistent condition characterized by positive and negative symptoms. Positive symptoms can include hallucinations, delusions, thought disturbances, and persistent odd behaviors, such as the risks of violent behavior (RVB) [1], [6].

RVB is one of the angry responses expressed by threatening to injure other people and damage the environment [7]. The cognitive response of risks of violent behavior changes and affects the speed of their thinking process [8]. It causes an inability to solve problems and perform social-cognitive actions. This condition makes patients with schizophrenia conduct violence to other people [9]. Further, behavioral responses try to attack and intimidate others, fight, agitate, or feel anxious [10]. In addition, social responses observed in patients with schizophrenia with RVB are verbally threatening to real or imaginary objects, attention-disturbing demands, and high speech intonation based on the notions or contents of paranoid thoughts and negative thoughts attitudes [11].

RVB occurs due to cognitive responses that result in slow thinking processes. It causes the inability to solve problems and perform social-cognitive actions [10]. This condition makes patients with schizophrenia act violently toward other people [8], [12]. They experience failure to manage their emotions when negative situations happen, and their expressions of emotion result in maladaptive action and lack empathy [13]. Psychotherapy is highly recommended to overcome this problem [14]. CBT is psychotherapy that can control the risks of violent behavior [15]. CBT is psychotherapy by building principles to connect thoughts, emotions, and behavior. The treatment given 
to CBT is to prioritize patients with schizophrenia' understanding of experiencing symptoms and using strategies to overcome these symptoms [16].

In addition, patients with schizophrenia require skills to socialize well without showing anger and threatening others. The exercise can be trained by providing social skills training (SST) [17]. SST is a psychological intervention focusing on developing or improving social interactions, social appearance, or interpersonal skills [18].

\section{Methods}

The design of this study was quasi-experimental without a control group. This study aimed to determine changes in the RVB after obtaining CBT and SST.

The CBT intervention included four sessions and SST included five sessions. One meeting was conducted 1 day, and the duration of each meeting varied from 30 to $45 \mathrm{~min}$. Further, the intervention was performed with the help of the patients with schizophrenia' workbooks and diary books. The first CBT session identified unpleasant experiences that caused automatic negative thoughts and behavior. Then, this session changed into positive thoughts and behavior. The second meeting was implemented to change the second automatic negative thoughts and behavior into positive ones. The third session was applied the support system inside and outside the family. The fourth session evaluated the benefits of the therapy. On the $5^{\text {th }}$ day, the program was continued with the SST. The first session of SST was teaching techniques to get acquainted with the patients with schizophrenia. The second session of the SST was training patients with schizophrenia to make friendships. In the third session, the patients with schizophrenia were trained to work in a group. In the fourth session, they learned to overcome difficult situations. The fifth session was the last session of the SST. In this session, they evaluated the therapeutic benefits given.

\section{Population and sample}

The study population was 74 patients with schizophrenia in the Utari room of Dr. H. Marzoeki Mahdi Hospital from February 11 to April 12, 2019. The research samples were 30 patients with schizophrenia selected by a consecutive sampling technique. The inclusion criteria of the sample were literate patients with schizophrenia, patients with schizophrenia, and patients with schizophrenia with RVB. The exclusion criteria were schizophrenic patients with schizophrenia with a verbal communication disorder or mental retardation.

\section{Statistical analysis}

The statistical analysis used a t-test using SPSS 21. The data were collected using questionnaires on signs and symptoms of RVB. The questionnaires were from the Mental Health Nursing Department, Universitas Indonesia, and were validated. The instrument validity test of RVB resulted in 26 valid sign symptoms. The R-values of the question items were $0.390-0.868>$ from 0.361 (value of R-table). In addition, the reliability test shows that Cronbach's coefficient-alpha was 0.791-0.906 (>0.6). The questionnaires consisted of five components: Cognitive, affective, physiological, behavioral, and social aspects.

\section{Ethical clearance}

The researchers guaranteed all patients with schizophrenia's rights to participate in the research. The research ethics were obtained from the Faculty of Nursing Ethics Committee of Universitas, Indonesia, with SK-248/UN2.D1.2.1/ETIK.FIK.2019.

\section{Results}

Table 1 shows that the average age of the patients with schizophrenia is 35-years-old. The duration of illness is 8 years, and the length of stay is 23 days. Meanwhile, the number of hospital admissions was 2 times. The normality test found that the variable frequency of hospital admission was normally distributed, but the variables of age, duration of illness, and length of stay were not normally distributed.

Table 1: Characteristics of the RVB patients with schizophrenia

\begin{tabular}{lllll}
\hline Variables & Means & Median & SD & Min-Max \\
\hline Age & 35.1 & 33.0 & 7.9 & $23-59$ \\
Length of illness (in years) & 8.6 & 6.0 & 8.6 & $1-33$ \\
Treatment frequency & 2.6 & 3 & 2.7 & $0-13$ \\
Length of stay (in days) & 23 & 23 & 1.3 & $21-27$ \\
\hline
\end{tabular}

Table 2 signifies that the composite symptom score of signs and symptoms of risks of violence before CBT is 10.45 (43.3\%). This figure means that each respondent experienced 10.4 of 24 totals of violent risk behavior symptoms. After the respondents had received the $C B T$, the signs and symptoms decreased to $5.41(22.51 \%)$. After the respondents had received the CBT and SST, the score of risks of violent behavior symptoms increased to $0.52(2.16 \%)$, while the score of signs and symptoms before and after the CBT and SST decreased from $10.4(43.3 \%)$ to $0.52(2.16 \%)$. The average score of difference is 9.96 . This study revealed significant differences in the scores of violent risk behavior symptoms before and after the CBT and SST interventions $(p<0.05)$. 
Table 2: Effects of the cognitive behavior therapy and social skill training on RVB patients with schizophrenia $(n=30)$

\begin{tabular}{|c|c|c|c|c|c|c|c|c|}
\hline \multirow[t]{2}{*}{ Variables } & \multirow[t]{2}{*}{ Mean before CBT } & \multirow[t]{2}{*}{ Mean after CBT } & \multirow[t]{2}{*}{ Mean after CBT+SST } & \multirow[t]{2}{*}{ Mean diff. } & \multicolumn{3}{|l|}{ (Min-Max) } & \multirow[t]{2}{*}{$\mathrm{p}$-values } \\
\hline & & & & & Before CBT & After CBT & After CBT+SST & \\
\hline Cognitive & 3.33 & 1.63 & 0.03 & 3.33 & 3.6 & $0-1$ & $0-1$ & $0.00^{*}$ \\
\hline Affective & 1.70 & 0.86 & 0.10 & 1.60 & $2-3$ & $0-1$ & 0 & $0.00^{*}$ \\
\hline Physiology & 1.83 & 0.96 & 0.13 & 1.70 & 2.7 & $0-1$ & $0-1$ & $0.00^{*}$ \\
\hline Behavior & 1.93 & 1.0 & 0.13 & 1.80 & $2-3$ & $0-1$ & $0-1$ & $0.00^{*}$ \\
\hline Social & 1.66 & 0.96 & 0.13 & 1.53 & $2-3$ & $0-1$ & 0 & $0.00^{*}$ \\
\hline Composite & 10.45 & 5.41 & 0.52 & 9.96 & 7.00 & 5.00 & 1.00 & 0.00 \\
\hline
\end{tabular}

\section{Discussion}

Our study found that the combination of CBT and SST has positive changes in the sign and symptoms of RVB patients with schizophrenia. These changes also positively impact the ability of patients with schizophrenia to control their symptoms.

RVB must be treated initially to control patients with schizophrenia' behavior and emotions. RVB can occur due to the patients with schizophrenia' irrational thoughts or negative automatic thoughts [8]. Negative thoughts significantly influenced the patients with schizophrenia' feelings and behavior. The negative behavior and emotions experienced by RVB patients with schizophrenia result from interpreting events; they experience in their lives. In addition, RBV occurs due to extreme conditions that result in maladaptive coping mechanisms [12].

CBT is psychotherapy by building principles to connect thoughts, emotions, and behavior. The treatment given to CBT is to prioritize the patients with schizophrenia' understanding of experiencing symptoms and using strategies to overcome these symptoms [16]. Through CBT, patients with schizophrenia train their rational thinking to get a more reasonable explanation of psychotic experiences; and thus, they can accept conditions logically [19]. CBT stimulates the patients with schizophrenia' ability to reflect or evaluate a condition using their logical thoughts [20]. Therefore, CBT can be chosen as a psychosocial therapy to overcome the automatically negative to positive thought and behavior. The results of this study are similar to those of other studies revealing that CBT can decrease signs and symptoms [21].

The CBT provides benefits to make patients with schizophrenia aware of signs and symptoms; they experience through therapeutic communications to build a trusting relationship, change negative behavior into adaptive cognitive coping behaviors, develop an understanding of psychotic experiences, such as hallucinations and delusions causing the RBV, and overcome social disorders. These abilities are conducted from the first to the last CBT sessions [22], [23].

After being evaluated during the second meeting, the patients with schizophrenia' signs and symptoms decreased, becoming more relaxed than before. Signs and symptoms of behavioral aspects such as loud voice, speaking rudely, and unable to calm significantly decreased. This condition could reduce negative behavior because the patients with schizophrenia started to express their feelings calmly. Negative thoughts caused permanent anger due to negative behavior that made the patients with schizophrenia silent, impulsive, and prone to insomnia [24]. Therefore, they received CBT to overcome this condition. Patients with schizophrenia became relaxed after receiving the CBT [20].

This study found that the problems were related to the treatment because the patients had wrong thoughts and opinions about this matter. An understanding of pain also helped the patients realize their treatment. This understanding is given through CBT because some patients had negative thoughts about the medication therapy, making them more likely to experience relapse [25].

CBT therapy brought several impacts, such as cognitive distortions, disturbing feelings to emotions without causing loss of self-awareness, social problems, and physiological problems. Kim et al. (2020) explain that patients' inability to recognize maladaptive thoughts and behaviors contributes significantly to the emergence of positive symptoms [12]. This condition disables them to find adaptive coping to deal with the situation experienced. The CBT can identify negative thoughts, and thus, patients can understand their problems, find assistance to recognize negative thoughts, and train themselves to become positive. If the patients understand positive thoughts, they can train themselves to handle negative behavior, such as violence from negative thoughts [26].

The CBT also increased patients' visions to fight negative thoughts. The impact of negative thoughts and behaviors on social problems became a problem for patients. The inability to deal with issues and conflicts made patients behave aggressively and deal with maladaptive matters. This problem is undoubtedly more burdensome for their conditions. Therefore, solving issues, establishing social relationships, and maintaining relationships with other people are necessarily trained. This skill can pass through the SST method.

Social skills training (SST) is a psychological intervention focusing on developing or improving social interaction, social appearance, or interpersonal skills [18]. The patients with schizophrenia have received social skills training to reduce signs and symptoms of 
RVB and improve their ability to socialize [27]. The SST for patients with schizophrenia with RVB increased their socialization and enhanced their social skills [28]. The SST in this study emphasized that patients with schizophrenia practiced making friends, working in a group, and dealing with difficult situations. These actions aimed to train them to work together and manage emotions to establish social relationships without verbal or non-verbal violence against others. The SST session emphasized that patients with schizophrenia could manage their abilities. The provision of the CBT undoubtedly influenced the results in the previous sessions. Consequently, the CBT and SST, conducted in a short time, could reduce the signs and symptoms of RVB [17].

Practices against negative thoughts and behaviors caused anger; utilizing support systems from the family and community were critical to overcoming patients with schizophrenia' mind disorders [21]. Ability was necessary to maintain their conditions. Meanwhile, exercises, such as social interaction with family or other people, could maintain their ability. This social-related practice emphasized how patients with schizophrenia could interact without showing aggressive symptoms.

\section{Conclusion}

Cognitive behavior therapy and social skill training can decrease the signs and symptoms of the risks of violence and enhance patients with schizophrenia' abilities of the risks of violent behavior.

\section{Suggestion}

Nurses who have been trained and have certificates necessarily perform continuous therapies, namely, the CBT and SST, to assist patients with violent behavior problems to overcome their health problems and realize the effects of aggressive thoughts and behavior. As a result, they can continuously improve their ability to overcome health problems. Moreover, these therapies must be supported by adequate mental nursing services for patients during hospitalization and outpatient treatment.

\section{References}

1. WHO. Schizophrenia. Geneva: WHO; 2019. Available from: https://www.who.int/news-room/fact-sheets/detail/ schizophrenia. [Last accessed on 2019 Oct 04].

2. Metrics GH. Schizophrenia Level 3; 2019. Available from: http://www.healthdata.org/results/gbd_summaries/2019/ schizophrenia-level-3-cause [Last accessed on 2019 Oct 04].

3. Kemenkes RI. Hasil Riset Kesehatan Dasar Tahun 2018. Jakarta, Indonesia: Kementrian Kesehat RI; 2018. p. 1689-99.

4. American Psychiatric Association. Diagnostic and Statistical Manual of Mental Disorders (DSM-5). Washington, DC: American Psychiatric Publishing; 2015.

5. Singh P, Midha A, Chugh K. Schizophrenia: Impact on quality of life. Indian J Psychiatry. 2008;50(3):181-6. https://doi. org/10.4103/0019-5545.43632

6. Stuart GW. Prinsip dan Praktik Keperawatan Kesehatan Jiwa Stuart. Singapura: Elsevier Inc.; 2016.

7. Budi AK, AkematA, Novy HC. Nurhaeni, Keperawatan Kesehatan Jiwa Komunitas: CMHN (Basic Course). Jakarta: EGC; 2012.

8. Lamsma J, Cahn W, Fazel S, Genetic Risk and Outcome of Psychosis (GROUP) Investigators. Cognition and violent behavior in psychotic disorders: A nationwide case-control study. Schizophr Res Cogn. 2020;19:100166. https://doi. org/10.1016/j.scog.2019.100166

PMid:31832346

9. McCleery KH, Ventura J, Kern RS, Subotnik KL, GretchenDoorly D, Green MF, et al. Consensus cognitive battery (MCCB) profile of impairment. Schizophr Res. 2015;157:33-9. https://doi. org/10.1016/j.schres.2014.04.039

10. McCleery A, Ventura J, Kern RS, Subotnik KL, GretchenDoorly D, Green MF, et al. Cognitive functioning in first-episode schizophrenia: MATRICS Consensus Cognitive Battery (MCCB) Profile of Impairment. Schizophr Res. 2014;157(1-3):33-9. https://doi.org/10.1016/j.schres.2014.04.039 PMid:24888526

11. Volavka J. Violence in schizophrenia and bipolar disorder Psychiatr Danub. 2013;25(1):24-33

PMid:23470603

12. Kim SJ, Jung DU, Moon JJ, Jeon DW, Seo YS, Jung SS, et al. Relationship between disability self-awareness and cognitive and daily living function in schizophrenia. Schizophr Res Cogn. 2021;23:100192. https://doi.org/10.1016/j.scog.2020.100192 PMid:33294392

13. Carbon M, Correll CU. Thinking and acting beyond the positive: The role of the cognitive and negative symptoms in schizophrenia. CNS Spectr. 2014;19 Suppl 1:38-52; quiz 35-7, 53. https://doi.org/10.1017/S1092852914000601 PMid:25403863

14. Peuskens J, Demily C, Thibaut F. Treatment of cognitive dysfunction in schizophrenia. Clin Ther. 2005;27 Suppl A: S25-37. https://doi.org/10.1016/j.clinthera.2005.07.015 PMid:16198199

15. Health Quality Ontario. Cognitive behavioural therapy for psychosis: A health technology assessment. Ont Health Technol Assess Ser. 2018;18(5):1-141.

PMid:30443277

16. Batinic B. Cognitive models of positive and negative symptoms of schizophrenia and implications for treatment. Psychiatr Danub. 2019;31 Suppl 2:181-4.

PMid:31158119

17. Rus-Calafell $M$, Gutiérrez-Maldonado J, Ortega-Bravo $M$, Ribas-Sabaté J, Caqueo-Urízar A. A brief cognitive-behavioural social skills training for stabilised outpatients with schizophrenia: A preliminary study. Schizophr Res. 2013;143(2-3):327-36. https://doi.org/10.1016/j.schres.2012.11.014.

PMid:23235141

18. Côté SM, Larose MP, Geoffroy MC, Laurin J, Vitaro F, Tremblay RE, et al. Testing the impact of a social skill training versus waiting list control group for the reduction of disruptive 
behaviors and stress among preschool children in child care: The study protocol for a cluster randomized trial. BMC Psychol. 2017;5(1):29. https://doi.org/10.1186/s40359-017-0197-9

PMid:28784179

19. Wykes T. Cognitive-behaviour therapy and schizophrenia. Evid Based Ment Health. 2014;17:67-8. https://doi.org/10.1136/ eb-2014-101887

PMid:25043430

20. Sivec HJ, Montesano VL. Cognitive behavioral therapy for psychosis in clinical practice. Psychotherapy (Chic). 2012;49(2):258-70. https://doi.org/10.1037/a0028256 PMid:22642528

21. Granholm E, Holden J, Link PC, McQuaid JR, Jeste DV. Randomized controlled trial of cognitive behavioral social skills training for older consumers with schizophrenia: Defeatist performance attitudes and functional outcome. Am J Geriatr Psychiatry. 2013;21(3):251-62. https://doi.org/10.1016/j. jagp.2012.10.014

PMid:23395192

22. Wiedemann G, Klingberg S. Psychotherapy of positive symptoms in the treatment of patients with schizophrenia psychosis. Nervenarzt. 2003;74(1):76-84. https://doi.org/10.1007/s00115-002-1330-3 PMid: 12596031

23. Liu Y, Yang X, Gillespie A, Guo Z, Ma Y, Chen R, et al. Targeting relapse prevention and positive symptom in first-episode schizophrenia using brief cognitive behavioral therapy: A pilot randomized controlled study. Psychiatry Res. 2019;272:275-83. https://doi.org/10.1016/j.psychres.2018.12.130

PMid:30594760
24. Darmedru C, Demily C, Franck N. Cognitive remediation and social cognitive training for violence in schizophrenia: A systematic review. Psychiatry Res. 2017;251:266-74. https:// doi.org/10.1016/j.psychres.2016.12.062

PMid:28219026

25. Sensky T, Turkington D, Kingdon D, Scott JL, Scott J, Siddle R, et al. A randomized controlled trial of cognitive-behavioral therapy for persistent symptoms in schizophrenia resistant to medication. Arch Gen Psychiatry. 2000;57(2):165-72. https:// doi.org/10.1001/archpsyc.57.2.165 PMid:10665619

26. Bighelli I, Huhn M, Schneider-Thoma J, Krause M, Reitmeir C Wallis $\mathrm{S}$, et al. Response rates in patients with schizophrenia and positive symptoms receiving cognitive behavioural therapy: A systematic review and single-group meta-analysis. BMC Psychiatry. 2018;18:380. https://doi.org/10.1186/ s12888-018-1964-8 PMid:30514268

27. Turner DT, McGlanaghy E, Cuijpers $P$, van der Gaag $M$, Karyotaki E, MacBeth A. A meta-analysis of social skills training and related interventions for psychosis. Schizophr Bull. 2018;44(3):475-91. https://doi.org/10.1093/schbul/sbx146 PMid:29140460

28. Horan WP, Kern RS, Tripp C, Hellemann G, Wynn JK, Bell $\mathrm{M}$, et al. Efficacy and specificity of social cognitive skills training for outpatients with psychotic disorders J Psychiatr Res. 2011;45(8):1113-22. https://doi.org/10.1016/j. jpsychires.2011.01.015.

PMid:21377168 